PROBLEMS

OF MANAGEMENT

IN THE $21^{\text {st }}$ CENTURY

Volume 2, 2011

\title{
COMPARISON OF BEST PRACTICE BENCHMARKING MODELS
}

\author{
Barbora Jetmarová \\ University of Pardubice, Pardubice, Czech Republic \\ E-mail: barbora.jetmarova@upce.cz
}

\begin{abstract}
A review of benchmarking literature exposed that due to the development there are different types of benchmarking and different benchmarking models. There are universal models, but also models uniquely developed for particular benchmarking types. Each model varies in terms of the number of phases involved, number of steps involved, application, etc. The research focuses on one of the most popular benchmarking types: best practice benchmarking. Best practice benchmarking describes the comparison of performance data obtained by studying similar processes or activities and identifying, adapting, as well as implementing the practices that revealed the best results. The research intends to propose best practice benchmarking model after reviewing existing benchmarking models in literature. Implementing successful benchmarking project requires more than abidance to the step-wise models. Factors, which have an impact on the adoption of best practices benchmarking models will be highlighted, because many companies are involved in benchmarking, but adoption of best practices is not as height as might be expected.
\end{abstract}

Key words: benchmarking model, best practice benchmarking, benchmarking cycle.

\section{Introduction}

In today's rapidly changing business word, managers, owners and investors need to know the current situation of the enterprise, business environment and competitors, in order to promote and maintain its position in the market. Appropriate knowledge allows them to take the right decisions when obtaining financial resources, in determining the optimal financial structure, in allocation of available funds, in the provision of trade credit, in the distribution of profits, etc. In addition, enterprises must be better, faster, and cheaper than their competitors. Enterprises have to consider and in many cases adapt or implement a wide range of innovative management philosophies, approaches, tools and techniques. One such management tool, that has been widely used is benchmarking.

Benchmarking is influenced by development of management systems, statistical methods and information technology. Benchmarking procedures improve constantly. Scientific information sources reveal that there are several ways to classify types of benchmarking. Different benchmarking methodologies have been developed and applied in various settings, all with varied phases and steps of the process. There is a large number of benchmarking models and orientation in them is not easy. This research focuses on best practice benchmarking and its models. Choosing the right methodology is an essential key in making benchmarking a success. Because implementing a successful benchmarking programme requires more than adherence to the step-wise programmes, the most critical factors are also subject of this investigations. 


\section{Benchmarking}

Benchmarking presents a continuous process of measuring systems, processes and products within the enterprise and its comparison with enterprise that is doing best practice. The aim of such measuring is to learn new practices and procedures and in particular to obtain information to improve business performance. There are many other definitions, which have been proposed for benchmarking by different authors. Only selected definitions will be focused on.

Modern benchmarking practice is aimed at importing and implementing best practices across the organization. The American Productivity and Quality Center (1996) defines benchmarking as: "The process of identifying, understanding, and adapting outstanding practices and processes from organization anywhere in the world to help your organization improve its performance." The simpler definition of benchmarking, which is widely accepted is: "The search for and implementation of best practices" (Camp, 1989). He also states: "Benchmarking is your key to become the best of the best." Yasin (2002) describes benchmarking as a technique that can be utilized to identify operational and strategic gaps, and to search for best strategies that would eliminate such gaps. According to Hyatt (2001) \& Ramabadron et al. (1997) benchmarking is the process of identifying superior performance or practices of other organizations and internalizing such knowledge for competitive advantage. Benchmarking is the activity of finding, learning, exchanging and adapting best practices, which makes benchmarking a positive, proactive process to change operations in structured fashion to achieve superior performance. Benchmark is performance objective, which incorporates best practice - the standard of excellence (Camp, 2004). Benchmarking becomes a process that establishes the ground for creative breakthrough, a process of identifying the highest standards of excellence for products and services, and then making the improvements necessary to reach those standards by addressing the management and operational skills responsible for production (Bhutta and Huq, 1999; Kozak and Nield, 2001). The key philosophy of benchmarking is the ability to recognize and acknowledge that someone is doing a better job, learn how it is being done and implement it in one's field of business (APQC, 1996). As evidenced in literature, most authors have provided almost similar view on benchmarking. Benchmarking definitions focuses on following major areas: measurement via comparison, identification of best practices, implementation, continuous improvement and systematic process in carrying out benchmarking activity (Sarkis, 2001; Ramabadron et al., 1997; Cooper et al., 1996; Maire 2002; Anand and Kodali, 2008) etc. Therefore, it is believed that these areas encompass pertinent aspects of any benchmarking process. Analysing various definitions, benchmarking can be simply describes as: a management tool for attaining or exceeding the performance goals by learning from best practices and understanding the process by which they are achieved.

\section{Classification of Benchmarking}

Benchmarking procedures improve constantly, because they are influenced by the development of management systems, statistical methods and information technology. There are various identifiable trends in the epistemology of benchmarking and several ways to classify types of benchmarking, depending on the focus of the benchmarking process. Types of benchmarking reflect what is compared and what the comparison is being made against. The fontal types involves comparisons of performance, process and strategic benchmarking; while the later involves internal, competitive, functional and generic comparisons (Barber, 2004).

Anand and Kodali (2008) summarized classification schemes of types of benchmarking from 13 different authors (Spendoliny, 1992; Codling, 1992; Partovi, 1994; Malec, 1994; Fong at al., 1998; Maas \& Flake, 2001, etc.). According to them there are following types of 
PROBLEMS

OF MANAGEMENT

IN THE $21^{\text {st }}$ CENTURY

Volume 2, 2011

benchmarking: internal, competitive, functional, process best practice, best-in-class, generic, external, strategic, operational, business-management, consultant study benchmarking, reverse engineering, product, relationship, performance, result, diagnostic, hooded, open, etc. Though we have such classification for benchmarking, there are different definitions that exists for each classification type of benchmarking. An explanation for each type seems to overlap with one another and thus seems to be inconsistent. A clear evidence to state that there is still lack of consensus about the classification of benchmarking. According to Bhutta \& Hug (1999) types of benchmarking are rather complementary than being exclusive. They can be chosen and combined for a specific purpose.

According to Mann (2010), there are two main categories: informal and formal benchmarking. Formal benchmarking is divided in two categories: performance benchmarking and best practice benchmarking (sometimes called process benchmarking by other authors). Best practice benchmarking is searching for the best way or solution by studying other organisations that are high performers in particular areas of interest. The gained knowledge is then analysed and in cases that the practice is feasible and appropriate, it will be adapted and incorporated in the organisation's own process (Mann et al., 2010). Against that performance benchmarking compares the performance level of a specific process to identify opportunities for improvement and to set performance targets. Performance benchmarking, which tents to be financially dominated and historically based provides little in the way of prediction. This type almost never tackle growth creation, innovation, and learning - key initiatives in today's information and intelligence-based economy and the source of new products, services and markets. Zairi (1994) identifies essential types of benchmarking in his taxonomy: internal benchmarking, competitive benchmarking, functional benchmarking and generic benchmarking. All four mentioned types can be classified under performance or process benchmarking.

\section{Best Practice Benchmarking}

Best practice benchmarking is the most powerful type of benchmarking. It describes the comparison of performance data obtained by studying similar processes or activities and identifying, adapting, as well as implementing the practices that revealed the best results. It is the process of finding and using ideas and strategies from outside particular enterprise and industry to improve performance in any given area. Best practice benchmarking focuses on "Action" - i.e. doing something with the comparison data and working out why other organisations are achieving higher levels of performance (Mann et al., 2010). Seeing best practices in actual operation elsewhere is the most convincing approach to silencing the disbelief (Camp, 2004).

During the evolution of benchmarking, there have been distinct phases of increasing interest in best practice benchmarking in last 15 years. (Camp, 2004). Phases include the search for performance benchmarks, the interest in process proficiency, the understanding and mastery of best practice, and the development of best practice models. It shows a great development in this area. Companies need to understand the shortcoming of the first phase - performance benchmarks and its measures, which tent to be financially dominated and historically based. Today's best practice models should be constructed to guide organization to the future - to be a key to understand, manage and face business challenges.

\section{Benchmarking Approaches/Models}

In order to get useful results from benchmarking it is necessary to keep a systemic approach. The methodology for best practice study is critical. Over time, different benchmarking models were developed, to explain and guide benchmarking process. Some of them have been evolved from the original ten-step, four-phase model developed by Xerox. The number of 
reported benchmarking models is extremely large. Watson (1993) cited 69 different models outlining the process of benchmarking. Kozak and Nield (2001) identified approximately 40

different models. Some models originates from organizations and others from researchers and consulting agencies. Anderson and Moen (1999) identified 60 different existing models, while he was identifying new model - the benchmarking wheel. Zairi \& Leonard (1994) benchmarked 14 different benchmarking models. Later on Anand \& Kodali (2008) benchmarked 35 different frameworks against each other in a search for a single, exemplary framework. Many organizations have their own guides, success stories, and benchmarking methodologies e.g. AT\&T, The Post Office, American Express, Xerox, Schmidt, Alocoa, APQC/IBC, TNT, McKinsey \& Company, BBC, Rover Oroup, Texas Instruments, and IBM (Al-Mashari, 2005).

It is obvious there is a large number of benchmarking models and orientation in them is not easy. The research intends to propose best practice benchmarking model after reviewing chosen benchmarking models.

\section{Best Practice Benchmarking Model}

Developing best practice through benchmarking is a critical activity in the business word. That is why the best practice benchmarking is the most powerful type of benchmarking. After reviewing, the published works related to benchmarking models, selective key models, which are possible to use for best practice benchmarking, were identified, chosen and subjected to more detail study. All chosen model are possible to use for best practice benchmarking. Most of the selected models is defined by consultants. This is not surprising, since benchmarking originated in the private business sector. Academic community is lagging in terms of providing and advancing benchmarking models. These ten models are classified in Table 1. Table 1 provides ten chosen models defined by different authors. The number of phases and steps of each model, the year of publication and also categorization under which was the model developed is mentioned.

Table 1. Benchmarking models.

\begin{tabular}{|l|c|c|c|c|}
\hline Authors & Year & Category & $\begin{array}{c}\text { Number of } \\
\text { steps }\end{array}$ & $\begin{array}{c}\text { Number of } \\
\text { phases }\end{array}$ \\
\hline Camp R.C. & 1989 & Consultant based & 12 & 5 \\
\hline Codling & 1992 & Consultant based & 12 & 4 \\
\hline Yasin \& Zimmerer & 1995 & Academic based & 10 & 5 \\
\hline Xerox Model & 1996 & Organisation based & 10 & 4 \\
\hline Harrington \& Harrington & 1996 & Consultant based & 8 & 5 \\
\hline Finningan & 1996 & Consultant based & 21 & 5 \\
\hline Fong et al. & 1998 & Academic based & 15 & 6 \\
\hline Andersen \& Moen & 1999 & Academic based & 8 & 5 \\
\hline Longbottom & 2000 & Academic based & 11 & 4 \\
\hline Maas \& Flake & 2001 & Consultant based & 10 & 5 \\
\hline
\end{tabular}

The steps of each model were critically analyzed and it was proof that each model differs not only in number of steps and phases, but also in content of these steps. However, the basics are usually very similar. Therefore, the number of phases and steps is not fundamental. Depending on which model enterprise use, benchmarking study is usually including following: identifying benchmarking subject, data collection, determining current gap, projecting future performance, communication findings, establishing goals, developing action plan, implementation. These are the main activities during benchmarking study. The question, which followed after exploration 
of mentioned models, was: "Is there the need for so many frameworks?" There may need to be only one basic model, which could every enterprise apply and adapt it to its conditions. After studying these specific models, the new model was created.

Figure 1 shows proposed model and its specific benchmarking cycle. It displays four phases of benchmarking - planning, data collection, analysis and adaptation. These phases fade into one another. On the left side of the picture, it is shown what happens within the own enterprise - where the benchmarking study is provided. The right side shows the steps happening within the competitor's enterprise which is doing best practices.

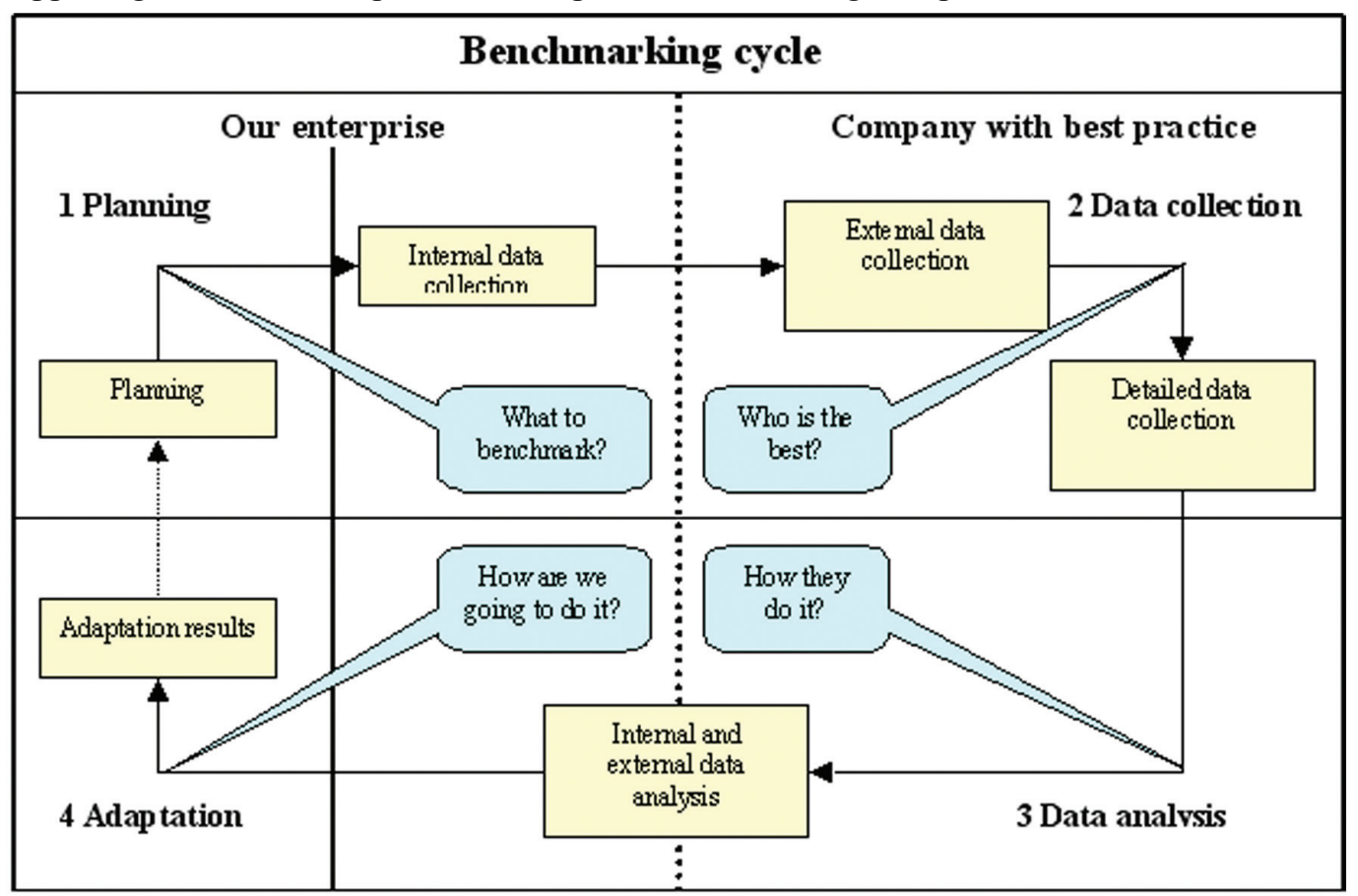

Figure 1: Best practice benchmarking cycle.

Finding appropriate answers to the questions: "What to benchmark?" and "Who is the best?" are regarded as critical factors of success. Motive power of benchmarking is to find answers to the questions: "How they do it?" and "How we are going to do it?" Recommended model consist of four phases, which are illustrated in Figure 1. These four phases includes 17 steps, which are stated in Table 2. 
Table 2. Benchmarking phases and steps.

\begin{tabular}{|l|l|}
\hline Phases & \multicolumn{1}{c|}{ Steps } \\
\hline Planning & $\begin{array}{l}\text { the subject of benchmarking defining, depth of benchmarking defining, objectives defin- } \\
\text { ing }\end{array}$ \\
\hline Data Collection & $\begin{array}{l}\text { internal data collection, external data collection, finding a benchmarking partner, contact } \\
\text { partner to ensure their consent and cooperation, gathering detailed data from bench- } \\
\text { marking partner, aggregate data about the partner from other sources }\end{array}$ \\
\hline Analysis & $\begin{array}{l}\text { converting data to information, sorting, organizing and monitoring the information and } \\
\text { data, removal of irregular factors (if any), detection performance difference with proven } \\
\text { best practices, discretion of the causes of the results, identification of processes which } \\
\text { can be improved, formulation of new goals, identification of plans for changes }\end{array}$ \\
\hline Adaptation & plan creation, implementation of best practices, connecting new plan with current plan \\
\hline
\end{tabular}

\section{Factors of Successful Benchmarking Application}

Successful implementation of benchmarking is not without difficulties. With a standard process framework - metrics, definitions, and best practices - the models are key to understanding and manage the challenges business has to face (Camp, 2004). For effective implementation of benchmarking is necessary to respect the benchmarking model, but simply applying certain approach will likely be insufficient according to Francis and Holloway (2007). Implementing a successful benchmarking programme requires more than adherence to the step-wise model. The most critical factors with a positive effect on the success of a benchmarking project are as follows:

- The support of top management is a crucial factor regarding the success of benchmarking project. In many situations, benchmarking teams faces obstacles within benchmarking projects that can only be solved with the help of a higher authority. The lack of support and involvement from the top management or even fellow colleagues is often caused due to a lack of benchmarking-understanding. Therefore, the promotion of benchmarking-knowledge is needed to launch a smooth project.

- High level of employee involvement in a benchmarking project is necessary. It is clear that if enterprise performs benchmarking projects in a professional manner, the gains from both the financial and non-financial perspective can be large.

- Benchmarking may be unsuccessful due to lack of managerial planning. Therefore, the preparation before the start of a benchmarking project and the evaluation at the end of a benchmarking project is important. (Mann et al., 2010)

- According to Francis and Holloway (2007) previous implementation experience, good interdisciplinary working, top management commitment and realistic resources are characteristics associated with benchmarking implementation success.

- Huq et al. (2008) reported that failure to priorities internal situation before seeking exemplars elsewhere considerably increased the risk of implementation failure.

\section{Discussion}

Based on the rewiev of the benchmarking literature, which examined the curent benchmarking approaches, types and models, the following conclusions are derived. Large number of benchmarking models shows that benchmarking is popular management tool. It is obvious that the development and utilization of benchmarking practices continue to grow. Despite the increasing scope of benchmarking ativities and the number of organisations utilizing benchmarking, there is not an unifying theory in the field of benchmarking. Different autors 
PROBLEMS

OF MANAGEMENT

IN THE $21^{\text {st }}$ CENTURY

Volume 2, 2011

proposed different benchmarking types and different definitions exists for them. An explanation for each type seems to overlap with one another and thus seems to be inconsistent may be an evidence to state that there is still lack of consensus about the classification of benchmarking. Many consultant based models was selected. This is not surprising, since benchmarking originated in the private business sector. Academic community is lagging in terms of providing and advancing benchmarking models. Indeed, it is necessary to emphasize the importance of both approaches.

\section{Conclusions}

Benchmarking has become almost obligatory for any organization wanting to improve its products, services, or processes to better serve customers and improve business results. Especially best practice benchmarking will be strategic need for organizations as it is pursued to find and emulate best practices wherever they exist to close the gap and attain superiority. In this research, benchmarking definitions, types and models were reviewed. There is a large number of benchmarking models and orientation in them is not easy. Recent articles on the models of benchmarking are reviewed and used to construct a four-step benchmarking model. The proposed four-step model is advised to be use in facilitating and guiding benchmarking, thereby enabling enterprises to gain the full potential of benchmarking application. The proposed model consists of 4 main phases which includes 17 steps. Further research will be taken up in regards to develop a model which will contain factors of successful benchmarking application.

\section{Acknowledgements}

The article was supported by the "Student Grant Competition" at University of Pardubice - the project "Science and research activities supporting the program Economics and Management" - SGFES03/2011.

\section{References}

Al-Mashari, Majed. (2005). The role of benchmarking in best practice management and knowledge. The Journal of Computer Information Systems, Vol. 6, No. 3, p. 5-10.

Anand, G., \& and Kodali, R. (2008). Benchmarking the benchmarking models. Benchmarking: An International Journal, Vol. 15, No. 3, p. 257-291.

Anderson, B., \& Moen, R. M. (1999). Integrating benchmarking and poor quality costmeasurement for assisting the quality management work. Benchmarking: An International Journal, Vol. 6 No. 4, p. 291301 .

American Productivity \& Quality Center (APQC) (1996). Emerging Best Practices in Knowledge Management. Houston, Texas: American Productivity \& Quality Centre.

Barber, E. (2004). Benchmarking the management of projects: a review of current thinking. International Journal of Project Management, Vol. 22, No. 4, p. 301-307.

Bhutta, K. S., \& Huq, F. (1999). Benchmarking best practices: an integrated approach. Benchmarking: An International Journal, Vol. 6, No. 3, p. 254-68.

Camp, R. C. (1989). Benchmarking: The Search for Industry Best Practices that Lead to Superior Performance. Milwaukee, Wisconsin: ASQC Quality Press.

Camp, R. C. (2004). Best practice Benchmarking: The Path to Excelence. New York, USA: Best Practice Institute. 
Coopers, B. J., Leung, P., \& Mathews, C. M. H. (1996). Benchmarking a Comparison of International Audit in Australia, Malaysia and Hong Kong. Managerial Accounting Journal, Vol. 11, No. 1, p. 23 -29 .

Codling, S. (1992). Best Practice Benchmarking: The Management Guide to Successful Implementation. London: Gower Publishing Ltd.

Finnigan, J. P. (1996). The Managers Guide to Benchmarking. San Francisco, California: Jossey-Bass Publisher.

Fong, S. W., Cheng, E. W. L., \& Ho, D.C.K. (1998). Benchmarking: a general reading for management practitioners. Management Decision, Vol. 36, No. 6, p. 407-18.

Francis, G., \& Holloway, J. (2007). What have we learned? Themes from the literature on best-practice benchmarking. International Journal of Management Reviews, Vol. 9, No. 3, p. 171-89.

Harrington, H. J., \& Harrington, J. S. (1996). High Performance Benchmarking: 20 Steps to Success. New York: McGraw-Hill.

Huq, F., Abbo, M. H., \& Huq, Z. (2008). Perceptions about benchmarking best practices among French managers: an exploratory survey. Benchmarking: An International Journal, Vol. 15 No. 4, p. 382-401.

Hyatt, L. (2001). Benchmarking: How Does Your Organization Measure Up? Nursing Homes, Vol. 50, No. 5, p. 12-14.

Jetmarová, B. (2011). Benchmarking - Methods of raising company efficiency by learning from the bestin-class. E+M: Ekonomics and Management, Vol. 14, No. 1, p. 83-96.

Karlof, B., \& Svante, O. (1993). Benchmarking: A Signpost to Excellence in Quality and Productivity. New York: John Wiley \& Sons.

Kozak, M., \& Nield, K. (2001). An overview of benchmarking literature: its strengths and weaknesses. Journal of Quality Assurance in Hospitality Tourism, Vol. 2, No. 3/4, p. 7-32.

Longbottom, D. (2000). Benchmarking in the UK: an empirical study of practitioners and academics. Benchmarking: An International Journal, Vol. 7 No. 2, p. 98-117.

Maire, J. L., Bronet, V., \& France, A. (2005). A typology of best practices for a benchmarking process. Benchmarking: An International Journal, Vol. 12, No. 1, p. 45-60.

Malec, H. A. (1994). Benchmarking barometers for products and processes. Quality \& Reliability Engineering International, Vol. 10 No. 6, p. 455-65.

Mann, S. R., Abbas, A., Kohl, H., Orth, R., \& Görmer, M. (2010). Global Survey on Business Improvement and Benchmarking. Germany: Global Benchmarking Network.

Marwa, S., \& Zairi, M. (2008). A pragmatic approach to conducting a successful benchmarking expedition: Case of Dubai Holding Group (DHG). The TQM Journal, Vol. 20, No. 1, p. 59-67.

Maas, H., \& Flake, M. (2001). Environmental benchmark analysis of electr (on) ic products with components consisting of renewable raw materials. Proceedings of Second International Symposium on Environmentally Conscious Design and Inverse Manufacturing, Tokyo, Japan, December 11-15, p. 38891.

Ramabadron R., Dean, J. W., \& Evans, J. R. (1997). Benchmarking and Project Management: A Review and Organization Model. Benchmarking: An International Journal, Vol. 4, No. 1, p. 47-58.

Partovi, F.Y. (1994). Determining what to benchmark: an analytic hierarchy approach. International Journal of Operations \& Production Management, Vol. 14 No. 6, p. 25-39.

Yasin, M. M. (2002). Theory and practice of benchmarking: then and now. Benchmarking: An International Journal, Vol. 9, No. 3, p. 217-43.

Sarkis, J. (2001). Benchmarking for Agility. Benchmarking: An International Journal, Vol. 8, No. 2, p. 88-107. 
Spendolini, M. (1992). The Benchmarking Book. New York: American Management Association Communications (AMACOM).

Watson, G. H. (1993). Strategic Benchmarking. New York: Wiley.

Yasin, M. M., \& Zimmerer, T. W. (1995). The role of benchmarking in achieving continuous service quality. International Journal of Contemporary Hospitality Management, Vol. 7 No. 4, p. 27-32.

Zairi, M. (1994). Measuring Performance for Business Results. New York: Springer.

Zairi, M., Leonard, P. (1994). Practical Benchmarking: The Complete Guide. London: Chapman \& Hall.

Advised by Michaela Střiteská, University of Parubice, Pardubice, Czech Republic

Received: September 16, 2011

Accepted: October 23, 2011

Barbora Jetmarová Ing., Ph.D. Student, University of Pardubice, Studentská 85, Pardubice, Czech Republic. E-mail: barbora.jetmarova@upce.cz Website: http://upce.cz 